\title{
Виртуальные фотовыставки в современном медиапространстве
}

\author{
Мария Ромакина
}

В статье исследуется особая разновидность фотографических произведений - виртуальные фотовыставки, которые представляют собой цифровые объекты, чаще всего размещаемые в сети Интернет. Проведено сравнение характеристик виртуальных и аналоговых экспозиций по критериям, объединенным в две группы оппозиций: виртуальное материальное, открытое - регламентированное.

Проанализированы структурные, содержательные и коммуникативные особенности виртуальных фотовыставок. На конкретных примерах показано, что инициаторами их создания становятся различные организации - фотографические институции, музеи, библиотеки, СМИ, что в значительной степени определяет их специфику.

Ключевые слова: виртуальная фотовыставка, фотография, фотожурналистика, Интернет.

@ Ромакина Мария Александровна старший преподаватель кафедры фотожурналистики и технологий СМИ факультета журналистики МГУ имени М.В. Ломоносова (г. Москва, Россия), romakina@mail.ru
Стремительное развитие цифровых технологий и Интернета в начале XXI в. спровоцировало появление нового для фотографического рынка (и медиарынка в целом) явления - виртуальных фотовыставок. Это особого рода экспозиции, которые существуют в виртуальном пространстве и могут быть доступны зрителю в любой точке, обеспеченной доступом к Сети. Следует отметить, что появление и развитие виртуальных фотовыставок - лишь одно из проявлений процесса трансформации фоторынка, спровоцированного развитием цифровых технологий и Интернета. Проявление закономерное, поскольку они реализуют возможности органичного для цифровых снимков способа демонстрации - цифрового, виртуального, экранного.

Понятие «виртуальная фотовыставка» имеет несколько синонимичных вариантов - онлайн-, интернет-, электронная, цифровая фотовыставка (последние два малоупотребительны). Термин «выставка» в разных контекстах может заменяться близкими по значению словами «экспозиция», «галерея», иногда - «коллекция». Все эти определения описывают особый вид фотографических сообщений и, более широко, особый вид медиатекстов, демонстрирующих в электронном виде корпус фотографических изображений 
как единое высказывание на определенную тему. В настоящем исследовании автор ставит задачей изучить структурные, содержательные и коммуникативные особенности такого рода медиатекстов на примере виртуальных фотовыставок 2010 гг., а также сравнить их страдиционными аналоговыми экспозициями.

\section{Академические публикации о виртуальных выставках}

Наиболее значимыми в контексте исследуемых нами вопросов представляется несколько академических публикаций об онлайн-выставках. Статья М.Х. Урбанейя (2018) посвящена вопросу восприятия виртуальных выставок пользователями Сети именно как выставок. Автор провел исследование того, как посетители сайтов музеев определяют онлайн-экспозиции в качестве публикации или как выставки, опросив 20 человек относительно шести онлайн-экспозиций. Как выяснилось, экспозицию с большим количеством текстового наполнения почти все опрошенные воспринимают как «публикацию» (они действительно похожи по внешним признакам), а при доминировании визуального материала - как выставку. С.М. Матеос-Русилло и А. Джифро-Кастеллс (2017) разработали модель анализа онлайн-выставок, выделив три основные категории для анализа (дизайн, контент, степень соответствия), каждую из которых разделили на подкатегории. Так, категория «дизайн» включает подкатегории «навигация», «интерактивность», «взаимодействие с пользователем», а категория «контент» - подкатегории «виды контента», "размещение». С. Ким (2018) анализирует коммуникативные характеристики онлайн-выставок, также предпринимая попытку ввести категории («факторы» в терминологии С. Кима), позволяющие изучать их. Факторы он сначала разделяет на «зрительские» (имеющие отношение к посетителям) и «выставочные» (ха-

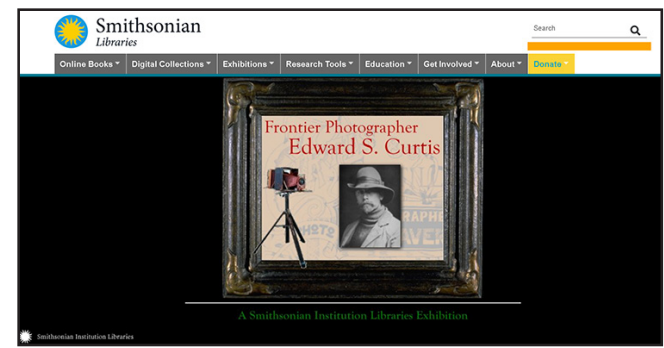

Рисунок 1. Пограничный фотограф Эдвард С. Кертис. Выставка библиотеки Смитсоновского института (1998-1999 гг.)

рактеризующие экспозицию). Затем делит первую группу на «персональные» и «социальные» факторы, а вторую - на «пространственные» и «содержательные». Дж. Купер (2006) рассматривает партисипаторные виртуальные экспозиции на примере проектов Музея изящных искусств в СанФранциско.

Кроме того, опубликован ряд статей, посвященных выставкам, инициируемым музеями и библиотеками, как продуктам, которые расширяют границы их деятельности, активизируя потенциал интернетпространства (Волькович, Чигарева, 2015; Пилко, Савкина, 2012, 2014 и др.). Существуют также работы, в которых даны практические рекомендации по созданию онлайнэкспозиций (Foo, 2008; Kalfatovic, 2002; Komianos, Oikonomou, 2019; Tinkler, Freedman, 1998). М. Калфатович в том числе приводит многочисленные примеры онлайн-выставок, среди которых есть и фотографические - например, экспозиция «Пограничный фотограф Эдвард С. Кертис. Выставка библиотеки Смитсоновского института»². На сегодняшний день она представляет собой не только художественный объект, но и исторический документ, отражающий возможности Интернета начала 2000 гг. (см. рис. 1). Таким образом, проанализированный нами корпус академических текстов затрагивает три группы проблем: 1) определение статуса онлайн-выставок, 
Таблица. Сравнительный анализ виртуальных и аналоговых фотовыставок

\begin{tabular}{|c|c|c|}
\hline $\begin{array}{l}\text { Критерии } \\
\text { сравнения }\end{array}$ & $\begin{array}{l}\text { Виртуальная } \\
\text { фотовыставка }\end{array}$ & $\begin{array}{c}\text { Аналоговая } \\
\text { фотовыставка }\end{array}$ \\
\hline $\begin{array}{l}\text { Форма } \\
\text { существования }\end{array}$ & $\begin{array}{l}\text { Виртуальная } \\
\text { (цифровой объект) }\end{array}$ & $\begin{array}{l}\text { Материальная } \\
\text { (физический объект, который } \\
\text { может включать виртуальный/ } \\
\text { цифровой компонент) }\end{array}$ \\
\hline $\begin{array}{l}\text { Режим } \\
\text { экспонирования } \\
\text { и просмотра }\end{array}$ & $\begin{array}{l}\text { Дистанционный, экранный } \\
\text { (не подразумевает перемещений } \\
\text { зрителя в пространстве, } \\
\text { только движения, связанные } \\
\text { с управлением экраном) } \\
\end{array}$ & $\begin{array}{l}\text { Вовлекающий, пространственный } \\
\text { (подразумевает перемещения } \\
\text { в пространстве галереи, музея, } \\
\text { уличной эскпозиции, телесную } \\
\text { вовлеченность зрителя) }\end{array}$ \\
\hline $\begin{array}{l}\text { Экспонируемые } \\
\text { объекты }\end{array}$ & $\begin{array}{l}\text { Двумерны, виртуальны } \\
\text { (цифровые фотографии или } \\
\text { изображения аналоговых } \\
\text { фотографий, т.е. их цифровые } \\
\text { копии) }\end{array}$ & $\begin{array}{l}\text { Трехмерны, материальны } \\
\text { (аналоговые изображения, } \\
\text { отпечатки цифровых снимков, } \\
\text { цифровые снимки на дисплеях, } \\
\text { проекции фотографий, } \\
\text { фотоскульптуры и т.д.) }\end{array}$ \\
\hline Доступность & $\begin{array}{l}\text { Открытый просмотр, большинство } \\
\text { экспозиций бесплатные } \\
\text { (определяется возможностями } \\
\text { выйти в сеть Интернет; } \\
\text { «расширенное» присутствие - } \\
\text { возможность гипертекстового } \\
\text { доступа с других ресурсов) }\end{array}$ & $\begin{array}{l}\text { Ограниченный просмотр, } \\
\text { большинство экспозиций платные } \\
\text { (доступ к экспозиции зависит от } \\
\text { графика работы музея/галереи/ } \\
\text { библиотеки/выставочного зала, } \\
\text { географической доступности } \\
\text { открытой площадки) }\end{array}$ \\
\hline
\end{tabular}

2) формирование категориального аппарата, позволяющего характеризовать их, 3) разработка «рецептуры» их создания.

Также важно упомянуть публикации, осмысливающие отдельные кейсы онлайнвыставок (Волькович, Чигарева, 2015; Пилко, Савкина, 2012; Cavazza, Mead, 2001; Daly, Ballantyne, 2009; Mundi, Burton, 2013, Romakina, 2019 и др.), кураторство в цифровой среде (Barker (ed.), 1999; Groys, 2018) и особенности бытования современного архива, его переходного статуса от статичного хранилища - к передаче данных³.

\section{Сравнительный анализ виртуальных и аналоговых фотовыставок}

Первичной исследовательской задачей является процедура определения границ и специфики виртуальных фотовыставок, что возможно сделать через их сравнение страдиционными, имеющими физическое измерение (условимся называть их аналоговыми, используя фотографическую терминологию доцифрового периода). Такое сравнение (см. табл.), с нашей точки зрения, позволяет говорить о двух основных оппозициях, которые их характеризуют: виртуальное-материальное, открытоерегламентированное. Если пространство галереи или уличной площадки характеризуется такими параметрами, как конфигурация, текстура и цвет стен, режимы освещения ит.д., что является «рамкой» для высказывания фотографа, то виртуальное пространство лишено этого. Галерея «отгорожена от внешнего мира», выставляемые в ней произведения «живут своей жизнью» (О'Догерти, 2015: 21), она «диктует» возможные способы выстраивания маршрута движения в пределах экспозиции, режимы телесного (зрительного, слухового, иногда тактильного) взаимодействия зрителя с выставочными объектами - фотографиями в рамах или без них, группами фотографий (Read, 2008), инсталляционными фотографическими произведениями, фотоскульптурами, дисплеями. Фотографические произведения, в том числе 
и цифровые, здесь материальны. Они имеют размер, что в отдельных случаях предельно значимо - например, для фотографий сверхбольшого формата, так называемых tableau (Lugon, 2010). Снимки напечатаны на бумаге той или иной текстуры и толщины, которая отражает/поглощает свет определенным образом, может заминаться, идти волной и подвергаться другим деформациям, что иногда становится частью фотографического высказывания. Снимки могут быть показаны на дисплеях или при помощи проекционного оборудования, которые также материальны. Они организованы в пространственные композиции (развеска всегда значима) и являются частью фотографического высказывания.

При экспонировании в Интернете выставки лишаются материального измерения, а зритель-возможности передвигаться в физическом пространстве, видеть, слышать и осязать это пространство. Цифровые фотографии здесь представлены в своем «естественном» виде - набором нулей и единиц, пикселями, тогда как аналоговые фотографии и остальные фотографические объекты-изображениями, копиями, электронными суррогатами (Lester, 2006). Пространство экспозиции ограничено размером экрана, что задает определенный масштаб смотрения, подразумевает камерность - такую выставку, как правило, «посещают» в одиночестве. В случае виртуальной фотовыставки дисплей выполняет функции галереи. Это приводит к тому, что в Интернете граница между выставкой и другими цифровыми объектами размыта. Только маркирующее определение «фотовыставка» иногда может свидетельствовать о том, что перед нами фотовыставка, а не онлайн-архив, публикация, блог. Визуальное повествование строится исходя из логики экрана и Интернета (система ссылок, организации страниц, интерактивность и т.д.).
Вторая оппозиция, открытое-регламентированное, отсылает прежде всего к возможности зрительского доступа к выставке. Локация галереи, режим ее работы, стоимость входного билета диктуют условия просмотра. К виртуальной выставке, размещенной в Интернете, есть доступ в любой момент времени, без входного билета (есть исключения, когда организаторы устанавливают плату за просмотр, но они редки). Виртуальную экспозицию, как правило, можно комментировать, делиться ссылками на нее в соцсетях, что в определенном смысле снимает дистанцию между организатором и зрителем. Интерактивность - одно из базовых свойств виртуальных экспозиций (Huntamo, 2010: 128). Также интернет-пространство позволяет оперативно корректировать информацию, трансформировать выставку в ходе ее экспонирования (в частности, такой трансформации подвергалась анализируемая нами в дальнейшем фотовыставка «Опыт перехода», которая меняла свой внешний облик при перемене web-адреса). То есть виртуальные фотовыставки являют собой «открытые» объекты и в содержательном отношении.

\section{Виртуальные фотовыставки 2010 гг.: анализ кейсов}

Нами было изучено 418 виртуальных фотовыставки на сайтах фотографических организаций, музеев, библиотек и СМИ. Для более подробного рассмотрения в рамках данной статьи автором отобрано 12. На их примере апробирована возможная методика анализа такого рода цифровых объектов. Авторская выборка призвана продемонстрировать максимальное разнообразие изучаемого вида объектов. Важно отметить, что степень известности экспонируемого автора не являлась решающим фактором при отборе 4 , приоритет был отдан тем выставкам, которые являются уникальными цифровыми экспо- 
зициями, демонстрирующими потенциал этой разновидности выставок.

Анализ проводился по трем основным критериям, которые представляют базовую значимость как для создателей виртуальных выставок и специалистов по их продвижению, так и для медиаисследователей, изучающих трансформации современных медиа: структура, содержание, коммуникативные особенности ${ }^{5}$.

Каждый из критериев является составным. Так, структуру онлайн-фотовыставки нам представляется целесообразным характеризовать через следующие параметры: общее количество экспонируемых фотографий, наличие дополнительных материалов (текст-концепция, справочный текст, графика и т.д.) и их взаимодействие с фотоконтеном ${ }^{6}$, конструкция экспозиции (сайт/слайд-шоу/мозаика/видеофайл и др.), маршрут перемещения зрителя (линейный/нелинейный), принцип организации материала (тематический/ хронологический/объектный/источниковый7). При разборе содержательных характеристик были выделены тематическая направленность выставки и ее проблематика, идейное поле. Коммуникативность будем определять через следующие параметры: степень интерактивности экспозиции (высокая/средняя/низкая)8, языковая доступность, ресурс размещения - сайт библиотеки/музея/СМИ и т.д. Также приведена информация об организаторах, кураторах и участниках, дате публикации ${ }^{9}$ и источниках фотоматериалов. Анализируемые фотовыставки представлены в хронологическом порядке (по убыванию, с 2019 по 2013 г.). Поскольку срок экспонирования во всех анализируемых в статье выставках открытый, а просмотр бесплатный, критерии «время функционирования» и «доступность» в исследование не включены.

1. «Ленинградцы! Все мы-бойцы фронта!» (Фотохроника ТАСC 1941-1943 (из фондов Отдела эстампов))10. Дата публикации - февраль 2019 г. Организатор - Российская национальная библиотека (РНБ). На выставке представлено 200 цифровых копий фотографий из фондов Отдела эстампов РНБ, которые были сделаны журналистами для «Фотохроники ТАСС» во время блокады Ленинграда. В оригинале фотографии представляют собой позитивные отпечатки, на оборотную сторону которых наклеены листы машинописного текста с информацией об авторе снимка, изображенных людях, деталях события. Помимо сопровождающего текста оборотная сторона также включает инвентарные номера «Фотохроники ТАСС» и РНБ. Выставка представляет изображения как лицевой, так и оборотной сторон отпечатков. Экспозиция включает значительный объем текста: исторические справки, подписи к экспонатам. Оформлена в виде отдельного web-сайта - одной из ветвей основного портала РНБ. Имеет многостраничную структуру (общее число страниц - 4: «О выставке», «Фотохроника», «Блокадная коллекция», «Интернет-ресурсы»). Согласно хроникальной логике фотографии разбиты на четыре блока, свидетельствующих о начале Великой Отечественной войны, начале блокады, жизни Ленинграда в 1942 г., прорыве блокады. Материалы организованы в виде вертикальной оси времени (timeline) на странице «Фотохроника». Маршрут движения зрителя - нелинейный: зритель определяет его самостоятельно, выбирая наиболее интересный период и активируя соответствующий корпус изображений. Принципы организации материала - тематико-хронологический, источниковый (представлены снимки только из одного архива - «Фотохроники ТАСС»). Выставка приурочена к 75-летию прорыва блокады. Название повторяет заголовок статьи, опубликованной в «Ленинградской правде» в 1941 г. вскоре после того, как кольцо блокады замкнулось. Это жизнеописание блокадного Ленинграда (бойцов, строителей оборо- 
нительных сооружений, диспетчеров железной дороги, медсестер и т.д.). Степень интерактивности - низкая, язык - русский, размещение - сайт библиотеки.

2. «Работы физиологической станции Этьена-Жюля Марея и Джорджа Демения»11. Opганизатор - Национальный музей спорта в Ницце, Франция (Le Musée National du Sport). Дата публикации - 17.01.2019. Выставка представляет постраничную экспозицию пятитомного издания 1886-1887 гг., посвященного хронофотографическим фиксациям движений животных и людей, снятых Э.-Ж. Мареем и его ассистентом Г. Демением. Общее количество изображений - 550. Каждый том экспонирован на отдельной webстранице и имеет свой заголовок - «Кинематический анализ движения живых существ. Устройства и фотографические методы» (т. 1, 116 изображений), «Движения человека» (т. 2, 125 изображений), «Сравнительная анатомия органов движения» (т. 3, 65 изображений), «Смеси» (т. 4, 98 изображений), «Человек/Лошадь» (т. 5, 146 изображений). Выставлены все страницы книг - текстовые, комбинированные (текст, фотографии, рисунки). Маршрут перемещения вариативен: нелинейный, свободный (при клике на иконки) или линейный (при активации режима слайд-шоу). Принцип организации материала - объектно-хронологический (последовательная демонстрация страниц книг). Цель выставки - представить широкому зрителю ценное как с фотографической, так и с научной (физиология) точки зрения издание. Степень интерактивности высокая, язык французский, ресурс - сайт музея.

3. «История Российской печати: от Петра до Интернета»12. Организатор - «История России в фотографиях»13. Дата публикации - 13.01.2019. Общее число изображений - 26 (24 черно-белых и одна цветная фотографии 1900-1996 гг., одна фототипическая открытка). Экспозиция организована в виде слайд-шоу. Первый снимок размещен в фоновом режиме размером во весь экран (он также повторен в слайд-шоу под номером 23), поверх него расположен кураторский текст. Остальные изображения имеют меньший размер, позволяя видеть в верхней части экрана общее меню проекта, а в нижней - подписи к снимкам. В подписи приводится информация о газете (ее издателе, идеологических особенностях, тематике, тираже, а также дополнительные интересные факты) или разъянение к сюжету (так, фото 11 сопровождается рассказом об устных газетах, которые появились в связи с нехваткой бумаги в 1920 гг., их чтение длилось от 45 мин. до часа, на самом фото изображена группа в момент прослушивания газеты). Текстовое сопровождение к снимкам представляет собой двухслойную конструкцию: при наведении курсора на текстовый блок вместо информации об издании появляется всплывающее окно с сообщением об авторе фотографии, дате ее создания, дается ее название. Зрительский маршрут линейный, задан способом организации выставки - закольцованное слайд-шоу, где одно фото следует за другим. Времен ных ограничений для просмотра каждого изображения нет. Принцип организации материала - гибридный (тематико-хронологический). Тема - пресса (выставка была приурочена ко Дню российской печати). Идея - показать практики создания, распространения, чтения и иных способов ${ }^{14}$ потребления бумажной прессы на фоне значимых исторических событий XX в. Степень интерактивности - средняя, язык - русский, размещена на сайте фотоинституции.

4. «Конструкты: создание изображений при помощи "моментальной" пленки»15. Opганизатор - онлайн-издание об аналоговой фотографии Analogue Forever Magazine, при поддержке производителя фотографического оборудования Polaroid Originals. Дата публикации - 12.12.2018. Выставка одновременно является конкурсом, по- 
бедитель которого в качестве приза получил фотопродукцию Polaroid. Общее количество экспонируемых изображений - 30 (27 черно-белых, три цветных). Представлены фотографии, в том числе напечатанные в экспериментальной технике (с переносом эмульсии на алюминиевую пластину, на лист акварельной бумаги), и коллажи 30 авторов, сопровождаемые текстом (концепция, подписи). Конструкция - страница на сайте СМИ. Маршрут перемещения - нелинейный: выставка представляет собой мозаику «иконок», которые можно увеличивать, последовательность просмотра не задана. Принцип организации материала тематический. Идея - показ разнообразия художественных решений, возможных на основе «обычной» моментальной аналоговой фотографии. Степень интерактивности - высокая, язык - английский, ресурс - СМИ.

5. «До и после 1968. Фотографические поводы, чтобы поговорить об этом 50 лет спустя»16. Организатор - Национальный институт документации для инновационных и образовательных исследований (Indire, Италия). Дата публикации - 26.04.2018. Выставка имела аналоговую форму (проводилась с 26.09.2017 по 12.10.2017 в культурном пространстве LibriLibri, Флоренция). Представляет собой комбинаторную конструкцию, объединяющую слайд-шоу и таймлайн (см. рис. 2). На фоне неподвижного «полотна» со схематичным изображением зрителей, которые смотрят выставку (мы видим их со спины), представлен таймлайн, по которому зритель перемещается, переключая виртуальные стенды с фотографиями (всего девять стендов, 24 фото). Маршрут перемещения зрителя - линейный, принцип организации материала - гибридный (тематический, хронологический, источниковый). Выставка посвящена образовательной системе Италии 1930-1960 гг., это попытка отрефлексировать зарождение студенческого движения 1968 г. в контекс-

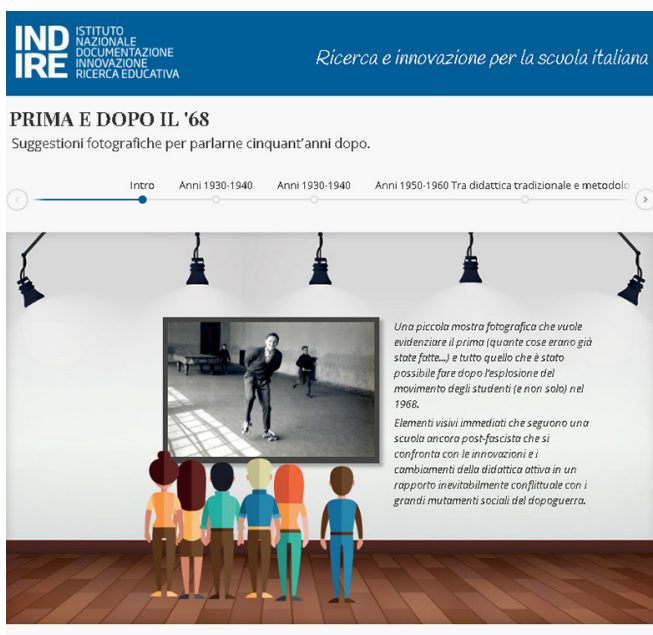

Рисунок 2. До и после 1968. Фотографические поводы, чтобы поговорить об этом 50 лет спустя (2018 г.)

те трансформаций системы образования в постфашистской Италии. Приурочена к 50-летию событий 1968 г. Степень интерактивности - низкая, язык - итальянский, ресурс размещения - сайт научной архивной организации.

6. "1917. Революция, которая изменила мир»17. Организатор - Международный центр фотожурналистики Перпиньяна. Дата публикации - октябрь 2017 г. Виртуальный вариант экспозиции, которая была представлена с 17 октября по 17 декабря 2017 г. в монастыре Миним (Couvent des Minimes) г. Перпиньян, преобразованном в настоящее время в публичное пространство. На выставке представлены снимки различных авторов, в том числе известных (В. Булла, К. Булла, Я. Штейнберг и др.) из коллекции М. Лефевра. Экспозиция имеет многочастную структуру - фотографии собраны в тематические блоки: «С февраля по октябрь. Революция», "Царь и война», «Все большевики», «Ленин», «Строительство СССР», «Троцкий». Заглавная страница фото 360 музейного зала с акустическим сопровождением (хоровое исполнение 


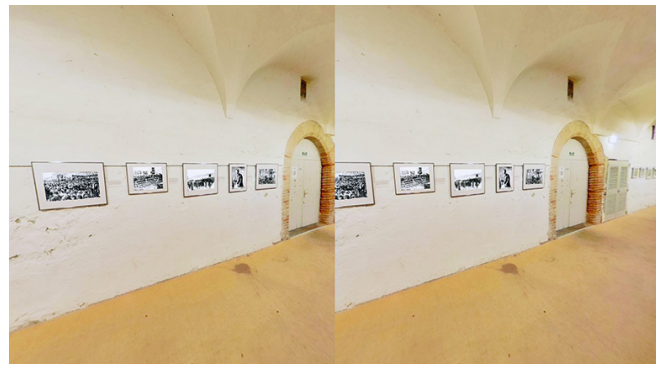

Рисунок 3. 1917. Революция, которая изменила мир (2017 г.)

гимна (ССР). Отдельные фотографии, фотомонтажи, тексты возможно укрупнять для подробного просмотра. Также есть опция просмотра видеокомментариев эксперта к отдельным фотографиям (на французском языке). Примечательно, что один из сопровождающих текстов позиционирует значимость фотографии в истории революции: «Русская революция изменила мир, она также изменила взгляд на мир. Советский Союз создал уникальную эстетику: политическая революция, социальная революция, графическая революция сошлись воедино. И фотография заняла важное место в этом революционном движении»18. Маршрут - линейный, повторяющий развеску в галерее. Формат виртуальной прогулки по залам галереи, возможен просмотр в VRгарнитуре (см. рис. 3). Принцип организации материала - тематический. Выставка посвящена октябрьской революции 1917 г., а также событиям, которые произошли до и после революции. Степень интерактивности - средняя, язык - французский, ресурс - сайт фотоинституции.

7. «Индустриальная фотография в эпоху машин»19. Организатор - международное некоммерческое объединение Photoconsortium в партнерстве с цифровой библиотекой Europeana. Дата публикации - 25.05.2017. Фотографии предоставлены различными партнерскими организациями (Parisienne de Photographie, Israel Museum, Alinari Archives, TopFoto, United Archives и др.). Всего 26 сним-

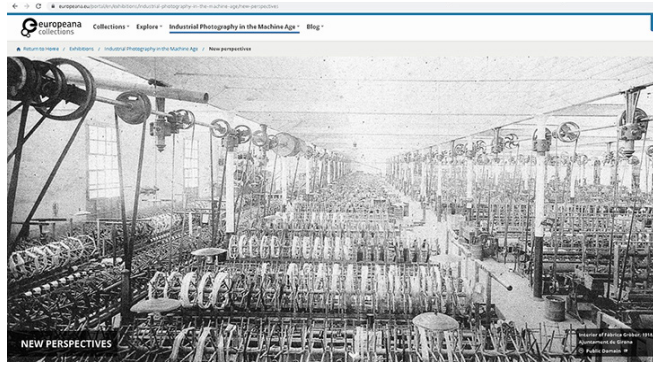

Рисунок 4. Индустриальная фотография в эпоху машин (2017 г.)

ков: заглавный (см. рис. 4) и те, которые собраны в различные тематические группы, - «Новые перспективы» (четыре), «Фабрики в фокусе» (шесть), «Ремесло» (пять, в том числе две стереопары), «Красота в банальности» (четыре), «Геометрия и линии» (шесть). Конструкция выставки напоминает многочастный лонгрид, где каждая часть состоит из текста, сопровождаемого иллюстрациями. Принцип организации экспозиции -тематический. Маршрут движения - нелинейный. Выставка посвящена индустриальной фотографии начала XX в. «Мы путешествуем во времени на фабрики, в города и мастерские начала XX в., открываем красивые образы в неожиданных местах», - провозглашено в кураторском тексте20. Гайки и болты, иглы и нити, шерсть и сталь, станки самого разного назначения, труженики у станков фотографии эстетизируют процесс производства материалов и изделий. Степень интерактивности - средняя, язык - английский, ресурс - сайт фотоинституции.

8. «Опыт перехода»21. Организатор «Фотодепартамент». Дата публикации 2017 г. Цифровая версия одноименной выставки, которая экспонировалась в галерее «Фотодепартамент» с 28 апреля по 10 мая 2017 г. Коллективная выставка (14 авторов) демонстрирует 15 проектов, включающих помимо фотографий (53) также видео (пять), gif-изображение, аудиофайл, текстовые сопровождения к проектам 


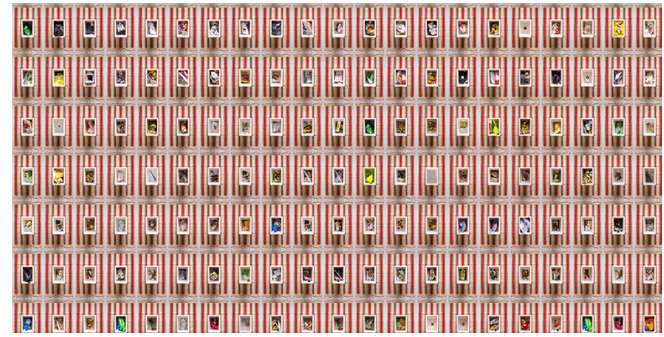

Рисунок 5. Калиниченко Л. <500> метров онлайн / Опыт перехода (2017 г.)

и навигационные инструменты (стрелки и т.д.), составляющие часть концептуального высказывания. Оформлена в виде отдельного сайта. Некоторые из работ различаются формой представления в материальном выставочном пространстве и цифровом. Так, проект «Ты слишком хорошая» А. Беспаловой в галерее имел инсталляционную форму и включал помимо фотографий объект (белую женскую блузку). В Интернете же он составлен из двух видео (фонового и нарративного), сопровождаемых текстами. Проект Л. Калиниченко «<500> метров онлайн» (см. рис. 5), который осмысляет проблему мусора в реальном и виртуальном пространстве, в цифровом виде связан с отсчетом времени, тогда как в галерее инсталляция была прежде всего пространственной, не временной. Проект С. Савченко «Сломанные часы» в Интернете интерактивен: зритель имеет возможность участвовать в замещении одних изображений другими, управляя этим процессом (см. рис. 6). «В физическом пространстве возможности восприятия не безграничны - зритель буквально упирается в стену. Эксперимент по равнозначному существованию выставки как единого высказывания в галерее и в digital-среде расширяет (и углубляет) осуществление опыта. Виртуальная среда изменчива и податлива, и зритель не только способен трансформировать объект наблюдения, бесконечно извлекая его из контекста и встраивая в новый, но и сам становится таким объек-

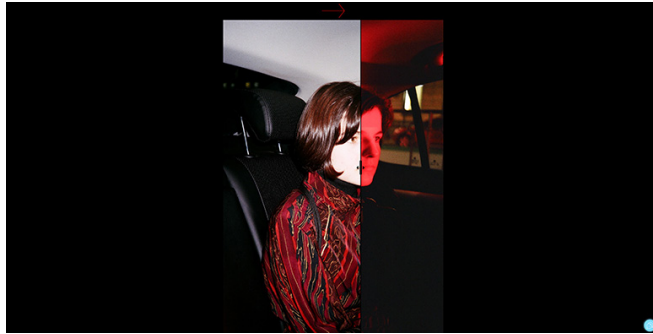

Рисунок 6. Савченко С. Сломанные часы / Опыт перехода (2017 г.)

том»22. Маршрут движения - нелинейный, разветвляющийся по вертикали и горизонтали. Скроллинг осуществляется по полотну лицевой страницы сайта с возможностью перехода на страницы отдельных проектов внутри сайта и на страницы проектов на сайтах авторов. Принцип организации материала - тематический, художественно-концептуальный (идея исследования фотографического медиума и различий экспонирования фотографических произведений в физическом и виртуальном пространстве). Концептуальный арт-проект, исследующий трансмедиальный переход, а также ставящий вопрос о том, что произойдет с фотографией, когда она станет использовать возможности Интернета как выставочного пространства, как будет меняться природа фотографического высказывания 23. Степень интерактивности средняя, язык - русский и английский, ресурс - отдельный сайт как ветвь сайта фотоинституции.

9. «Искусство фотографирования спорта: Смещение»24. Организатор - Олимпийский музей (The Olympic Museum) в Лозанне (Швейцария) в сотрудничестве с виртуальным музеем Google Arts \& Culture. Дата публикации - май 2017 г. Снимки участников конкурса «Мое импровизированное спортивное поле», присланные фотографамилюбителями из 15 стран. Однако в рамках фотовыставки имена авторов не указаны узнать победителей возможно на сайте фотоконкурса 25 . Представлены как фотогра- 
фии, так и фотомонтажи. Всего выставка включает 19 снимков, демонстрируемых в режиме слайд-шоу (маршрут - линейный). Перемещением от снимка к снимку управляет зритель, также запрограммирована возможность увеличивать каждое изображение. Принцип организации материала - тематический. Тема - спортивная фотография. Сюжеты снимков отображают выразительные фазы движений пловцов, боксеров, игроков в настольный теннис, танцоров и т.д. Степень интерактивности средняя, язык - английский, ресурс - сайт виртуального музея.

10. «В архив. О материальности фотографии»26. Организатор - The Digital Photo Library (Германия) и Художественно-исторический институт (Kunsthistorisches Institut / KHI, Флоренция, Италия). Дата публикации 14.11.2016. На выставке экспонировано 96 фотографий из фондов Государственного музея и Университета Гумбольдта в Берлине и Художественно-исторического института во Флоренции. Конструкция - шестистраничное экспонирование изображений экспонатов, которые сгруппированы по разделам. В шести разделах («Несколько оригиналов», «Работа с фотообъектами», «Тираж», «Люди в картинках», «Типы и типологии», «На полях архива») представлены коллекции четырех фотоархивов: Antikensammlung Staatliche Museen zu Berlin - Preußischer Kulturbesitz с фотографической документацией археологических кампаний в Магнезии, на Меандре и Пергаме; Sammlung Fotografie of Kunstbibliothek of Staatliche Museen zu Berlin - Preußischer Kulturbesitz с двумя группами архитектурных фотографий, датируемых приблизительно 1900 г.; фотоархив Hahne-Niehoff по фольклору Института европейской этнологии при Университете Гумбольдта в Берлине; Фототеки Kunsthistorisches Institut во Флоренции - Max-Planck-Institut с его отделом прикладного искусства. Каждая фотография снабжена подробной подпи-
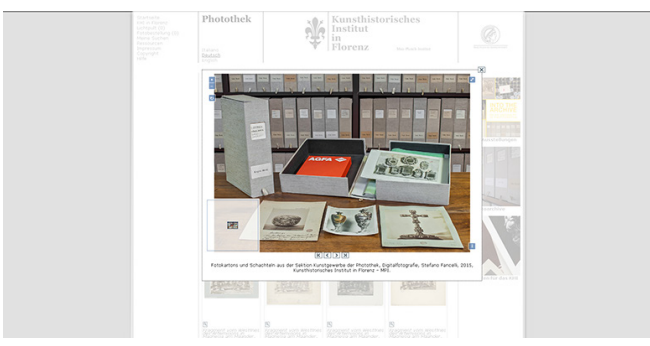

Рисунок 7. В архив. О материальности фотографии (2016 г.)

сью - название, описание ее материальной сущности (на картоне и проч.), дата создания, размер, инвариантный номер, автор, коллекция хранения (см. рис. 7). Есть фотографии, фотомонтажи, серии фотографий, стереопары, негативы, слайды. Принцип организации материала - тематический, источниковый (форма каталога). Тема сущность архива, историческая ценность документальной фотографии, важность внимание к «маргинальным» объектам переэкспонированным, не в фокусе, снимкам с дефектами. Идея деконструкции заявленной нейтральности документальных фотографий и фотоархивов. Исследовательский проект «Фотообъекты. Фотографии как исследовательские объекты в археологии, этнологии и истории искусств» (проводят четыре организации в сотрудничестве). Степень интерактивности - низкая, язык - английский и немецкий, ресурс сайт научной фотоинституции.

11. «Видимая работа, невидимые женщины: онлайн-выставка»27. Организатор - «Народный архив сельской Индии» (PARI). Дата публикации - 21.02.2015. 16 черно-белых снимков. Конструкция - страница web-сайта. Предлагается два варианта просмотра: страничная разверстка и слайд-шоу. Также зритель имеет возможность просмотреть видеозапись о выставке, которая экспонировалась в Индийском технологическом институте г. Канпура (IITKampur) в 2014 г.28 На выставке представлены репортажные зарисовки о повседневной жизни женщин 
в сельской Индии. Фотограф - П. Сайнат, фотографии сделаны в десяти штатах Индии в 1993-2002 гг., во время экономической реформы в стране (съемки завершились за два года до запуска Национальной программы гарантированной занятости в сельской местности). Степень интерактивности - средняя, язык - английский, ресурс - сайт архивной фотоинституции.

12. «Выставка автопортретов Lenscratch с уловкой - 2013»29. Организатор - онлайниздание о фотографии Lenscratch. Дата публикации - 14.02.2013. Фотографии (54) с подписями на одной странице, сопровождаемые вступительным текстом. Маршрут движения - линейный (скроллинг). Принцип организации материала - тематический. Приурочена ко Дню святого Валентина. Каждого автора, чье фото было отобрано на выставку, приглашали связаться с двумя другими авторами - теми, чьи снимки находятся выше и ниже в публикации. Степень интерактивности - низкая, языканглийский, ресурс - сайт СМИ.

\section{Заключение}

Проведенное исследование позволяет говорить о том, что понятие «виртуальная фотовыставка» объединяет широкий спектр цифровых объектов, представляющих собой сложные мультимедийные медиатексты, инициаторами создания которых становятся СМИ $(4,12)$, библиотеки $(1,10)$, музеи $(2,10)$, в том числе виртуальные музеи (9), фотографические институции $(3,6,7,8)$, архивные организации $(5,11)$. Цель создания экспозиции может быть различной - показ произведений современных фотографов (8), демонстрация архивного материала $(1,2,3,5,6,7,11)$, в том числе с научной целью (10), и даже проведение фотоконкурсов $(4,9,12)$. Показы архивных материалов чаще инициируют специализированные организации (библиотеки, музеи, архивные институ- ты), тогда как проведение фотоконкурсов прерогатива средств массовой информации и фотографических институций. Важно отметить, что для СМИ виртуальные фотовыставки открывают возможности интерактивного диалога с аудиторией, возможность вовлечения ее в процесс производства контента.

Изученный корпус экспозиций демонстрирует содержательную, структурную и коммуникативную вариативность виртуальных экспозиций, при создании которых цифровой код становится одним из «строительных материалов» (наиболее выразительный пример - выставка «Опыт перехода» (8), позволяющая пользователю участвовать в конструировании изображений). Принципиально важной представляется возможность создания сложной разветвляющейся (нелинейной) структуры онлайн-экспозиций, которая становится частью высказывания авторов и кураторов, а также всеобщая доступность таких выставок. Виртуальный способ экспонирования фотографий связан с дематериализацией фотографических произведений, демократизацией условий их предъявления зрителю и расширением временных границдемонстрации экспозиций (все анализируемые в статье выставки имеют открытый срок экспонирования). Понятие «фотовыставка» в интернет-пространстве выходит за привычные границы: трансформируется не только материальное в цифровое, но и само авторское и кураторское высказывание как таковое - идея сращивается с кодом, архив обретает "вечную жизнь», а зритель становится соавтором, в большинстве случаев при этом оставаясь невидимым и сохраняя статус анонимности.

Предложенная методика, сфокусированная на анализе трех упомянутых выше критериев (структура, содержание, коммуникативные особенности), может быть использована как базовая для изучения виртуальных фотовыставок в дальнейшем. Она 
позволяет рассмотреть подобные цифровые объекты как принадлежащие к единому классу, учитывая их индивидуальные особенности, и может быть расширена в соответствии с конкретными исследовательскими задачами.

\section{Примечания}

${ }^{1}$ Академических публикаций о виртуальных фотовыставках в научных базах и поисковых системах Cyberleninka, Elibrary, Elsiever, Google Scholar, Taylor\&Francis нами обнаружено не было, что, вероятно, объясняется достаточно коротким сроком их бытования, однако существуют публикации, посвященные онлайн-выставкам в целом. Изученный автором корпус текстов позволяет утверждать, что большинство поднимаемых ими проблем являются общими для разных видов виртуальных выставок (живописных, фотографических, архитектурных, экспозиций новых медиа, литературных, исторических и т.д.).

2 Frontier Photographer Edward S. Curtis. A Smithsonian Institution Library Exhibition. Peжим доступа: https://www.sil.si.edu/Exhibitions/curtis/. Онлайн-экспозиция имела физический прототип: с 23 сентября 1998 г. по 27 сентября 1999 г. выставка с одноименным названием проводилась в выставочном зале библиотеки Смитсоновского института (SI Libraries Gallery).

3 Schröeter J. Archive-Post/Photographic. Photo/Byte Media Art Net. Режим доступа: http://www.medienkunstnetz.de/themes/photo_byte/archive_post_photographic/

4 В качестве примеров виртуальных выставок известных фотографов и фотожурналистов возможно привести экспозиции работ Д. Ланж (Dorothea Lange, организатор - MOРА, 2017 г. Режим доступа: https://mopa.org/exhibitions/dorothealange/); Г. Паркса (Gordon Parks: A Harlem Family 1967, организаторы - The Gordon Parks Foundation, Google Arts\&Culture, 2013 г. Режим доступа: https://artsandculture. google.com/exhibit/gordon-parks-a-harlem-family-1967/uwKioUY0jnDHLg; http:// www.gordonparksfoundation.org/programming/educational-public/gordon-parksa-harlem-family-1967 и др.

5 При разработке методики анализа автор опиралась на опыт исследователей, изучавших онлайн-экспозиции в различных аспектах (Пилко, Савкина, 2014; Kim, 2018; Mateos-Rusillo, Gifreu-Castells, 2017).

6 Вопрос поликодовой, мультимодальной сущности онлайн-фотовыставок - тема отдельной публикации, в рамках данной статьи подробно не рассматривается.

7 Вводимая нами классификация - одна из возможных. Существуют и другие. Так, М. Калфатович (2002: 24-26) предлагает различать объектно-ориентированный и систематический принцип организации экспозиции. И. Пилко и С. Савкина (2012) выделяют следующие принципы структурирования: принадлежность залу, исторический, тематический.

8 Под интерактивностью мы будем понимать степень открытости экспозиции к взаимодействию с аудиторией. Высокая степень интерактивности предполагает: 1) возможность выстраивания маршрута просмотра; 2) возможность оценки или комментирования выставки и/или отдельных экспонируемых объектов и диалога с другими пользователями; 3) гипертекстовую открытость к распространению информации о выставке (встроенная опция поделиться ссылкой на 
выставку в социальных сетях и т.д.). Средняя степень интерактивности подразумевает наличие любых двух из этих возможностей, низкая - любой одной.

9 В тех случаях, когда организаторы выставки не предоставляют информации о дате ее открытия/публикации, информация была взята из анонсов в СМИ.

10 «Ленинградцы! Все мы - бойцы фронта!» («Фотохроника ТАСС 1941-1943 (из фондов Отдела эстампов))». Режим доступа: http://expositions.nlr.ru/ex_print/ blockade_photos/photos.php

${ }^{11}$ Travaux de la station physiologique par Etienne-Jules Marey et George Demenÿ. Peжим доступа: https://www.museedusport.fr/fr/page/expositions-virtuelles, http:// museedusport.jalbum.net/Marey-Demeny\%20-\%20Travaux\%20de\%20la\%20 Station\%20physiologique/

12 История российской печати: от Петра до Интернета. Режим доступа: https:// russiainphoto.ru/exhibitions/677/\#1

13 Проект разработан «Издательством Яндекса» при поддержке Министерства культуры Российской Федерации, Департамента культуры города Москвы, MAMM, а также компаний «Новатэк», «Норникель». Представляет собой общедоступный фотоархив, объединяющий коллекции из архивов организаций и частных архивов.

14 Газеты также используют утилитарно - для защиты от солнца (фото 21 - «Дом из Правды", а также фото 22, где из газет сделаны пилотки).

15 Constructs: Building Images with Instant Film. Режим доступа: https://www. analogforevermagazine.com/online-exhibitions/constructs-building-images-withinstant-film-december-2018

16 Prima e dopo il'68. Suggestioni fotografiche per parlarne cinquant'anni dopo. Режим доступа: http://www.indire.it/museo-virtuale/mostra-68/

171917 la révolution qui a changé le monde. Режим доступа: http://khent-hosting.fr/ Visite_virtuelle_CIP_Complet/Exposition\%20russie\%201917\%20CIP.html

181917 la révolution qui a changé le monde. Centre International de Photojournalisme Perpignan, Les Expositions. Режим доступа: http://photo-journalisme.org/fr/ expositions/

19 Industrial Photography in the Machine Age. Режим доступа: https://www.europeana. eu/portal/en/exhibitions/industrial-photography-in-the-machine-age

20 Industrial Photography in the Machine Age - virtual exhibition to be enjoyed in Europeana Photography. Photoconsortiunm. Net. 25.05.2017. Режим доступа: https://www.photoconsortium.net/industrial-photography-in-the-machine-agevirtual-exhibition-to-be-enjoyed-in-europeana-photography/

${ }^{21}$ Опыт перехода. Режим доступа: https://projection.media/projects/experienceoftransition/

22 Там же.

23 Выставка: Опыт перехода. Fotodepartament.ru, 2017. Режим доступа: http:// fotodepartament.ru/20564.

24 L'art de photographier de sport: Décalé. Режим доступа: https://www.olympic.org/ $\mathrm{fr} / \mathrm{musee} /$ decouvrir/programmation/e-expo-decale 
25 My DIY Sports Venue. The Olympic Museum, 2017. Режим доступа: http://museumphoto-contest.olympic.org/

26 Into the Archive. On Materiality of the Photograph. Режим доступа: http://photothek. khi.fi.it/documents/oau/00000303

27 Visible Work, Invisible Women: an online photo exhibition. Режим доступа: https:// ruralindiaonline.org/articles/sainath-womens-work-exhibition/

28 Visible Work, Invisible Women - Women and Work in Rural India (Video). People's Archive of Rural India. 8.09.2014. Режим доступа: https://ruralindiaonline.org/ articles/visible-work-invisible-women-women-and-work-in-rural-india-full-tour/

292013 Lenscratch self-portrait exhibition with a twist. Режим доступа: http:// lenscratch.com/2013/02/lenscratch-2013-self-portrait/

\section{Библиография}

Волькович А., Чигарева Н. Виртуальные выставки как новая форма деятельности музея // Труды С.-Петербургск. ин-та культуры, 2015. С. 250-254.

О'Догерти Б. Внутри белого куба. М.: Ад Маргинем, 2015.

Пилко И.С., Савкина С.В. Электронные выставки музеев и библиотек: сравнительный анализ // Вестн. Казанск. гос. ун-та культуры и искусств. 2012. № 2. С. 108-112.

Пилко И.С., Савкина С.В. Электронные выставки музеев: специфические особенности, видовая классификация // Вестн. КемГУКИ. 2014. № 29. С. 207-217.

Barker E. (ed.) (1999) Contemporary Cultures of Display. New Haven; London: The Open University Press/Yale University Press.

Cavazza M., Mead S.J. (2001) Virtual Art Galleries: A New Kind of Cultural Objects. Proceedings 2001 International Conference on Image Processing, vol. 1, pp. 590-593.

Cooper J. (2006) Beyond the On-line Museum: Participatory Virtual Exhibitions. In: Trant J., Bearman D. (eds.) Museums and the Web 2006: Proceedings, Toronto: Archives \& Museum Informatics. Режим доступа: http://www.archimuse.com/mw2006/papers/cooper/ cooper.html

Daly E., Ballantyne N. (2009) Retelling the Past Using New Technologies: A Case Study into the Digitization of Social Work Heritage Material and the Creation of a Virtual Exhibition. Journal of Technology in Human Services 27 (1): 44-56.

Groys B. (2018) Curating in the Post-Internet Age. Режим доступа: https://www.e-flux. com/journal/94/219462/curating-in-the-post-internet-age/

Foo S. (2008) Online Virtual Exhibitions: Concepts and Design Considerations. DESIDOC (Defence Scientific Information \& Documentation Centre). Bulletin of Information Technology 28 (4): 22-34.

Huntamo E. (2010) On the Origins of the Virtual Museum. In: Parry R. (ed.) Museums in a Digital Age. London, New York: Routledge, pp. 121-135.

Kalfatovic M.R. (2002) Creating a Winning Online Exhibition: A Guide for Libraries, Archives, and Museums. Chicago and London: Amer Library Assn Editions.

Kim S. (2018) Virtual Exhibitions and Communications Factors. Museum Management and Curatorship 33 (3): 243-260.

Komianos V., Oikonomou K. (2019) A Prototype System of Automatic Design of Virtual Exhibitions Integrating Cultural Assets from Public Repositories. Proceedings of 1st International 
Workshop on Visual Pattern Extraction and Recognition for Cultural Heritage Understanding colocated with 15th Italian Research Conference on Digital Libraries (IRCDL 2019), pp. 107-118.

Lester P. (2006) Is the Virtual Exhibition the Natural Successor to the Physical? Journal of the Society of Archivists 27 (1): 85-101.

Lugon O. (2010) Avant la "forme tableau». Le grand format photographique dans l'exposition «Signs of Life» (1976). Études photographiques 25: 6-41.

Mateos-Rusillo S.M., Gifreu-Castells A. (2017) Museums and Online Exhibitions: a Model for Analysing and Charting Existing Types. Museum Management and Curatorship 32 (1): 40-49.

Mundi J., Burton J. (2013) Online Exhibitions. Museums and the Web 2013. April 17-20, Portland, OR, USA. Режим доступа: https://mw2013.museumsandtheweb.com/paper/ online-exhibitions/

Read Sh. (2008) Exhibiting Photography. A Practical Guide to Choosing a Space, Displaying your work, and Everything in between.Burlington, Oxford: Elsevier/Focal Press.

Romakina M. (2019) The Photo Archive as Media: Between Exhibition, Collection and the Blog. International Conference on Communication and Media Studies: Media, Data, Society. Abstracts, pp. 11-12.

Tinkler M., Freedman M. (1998) Online Exhibitions: A Philosophy of Design and Technological Implementation. Museums and the Web 1998. Режим доступа: http://www. museumsandtheweb.com/mw98/papers/tinkler/tinkler_paper.html

Urbaneja M.H. (2018) Is This An Exhibition or a Publication? Defining Online Resourses Types in Art Museums. Proceeding of the International Conference Museums and the Web 2018 (MW18). Режим доступа: https://mw18.mwconf.org/paper/is-this-an-exhibitionor-a-publication-defining-online-resources-types-in-art-museums/ 